Public Health and Medicine in the U.S.S.R.

THE World Health Organization has issued a useful introductory guide to published material on public health and medicine in the U.S.S.R., based mainly on the holdings of the libraries of the World Health Organization and of the United Nations in Geneva (Library News, 13, Supp. No. 2. Pp. 130. Geneva: World Health Organization, 1960). Works published during 1946-60 are included, but the emphasis is on those published since 1954, and on translations, surveys, etc., chiefly in English and French. The material is arranged under nine sections: guides to Soviet medical and scientific publications; periodicals (including a list of cover-to-cover translation journals); abstracting and indexing periodicals ; bibliographies ; directories; dictionaries and encyclopædias; administrative material ; surveys; and miscellaneous material. The section dealing with administrative material is limited to publications issued in the U.S.S.R. ; in the remaining sections works published in the U.S.S.R. and works published outside the U.S.S.R. are listed separately. Most of the entries are annotated and there is an alphabetical index.

\section{U.S. Scientific Programmes in the Antarctic}

THE September issue of the IGY Bulletin, published by the National Academy of Sciences, provides a review of the status of the United States scientific programmes in the Antarctic, including many results of the International Geophysical Year and subsequent investigations, as well as descriptions of programmes in progress at the moment. The report contains contour maps showing the thickness of the Antarctic ice-cap and surface elevations; a description of the Echo I communications satellite, and of the long-range communications experiment for which it was designed as a 'passive' reflector of radio signals ; and a summary of solar activity, geomagnetic disturbances, and decisions of the World Warning Agency during International Geophysical Co-operation 1959, just past the peak of sunspot activity reached during the International Geophysical Year; the relationship of solar activity and its associated terrestrial effects during the International Geophysical Co-operation 59 period to the 11-year-old solar-cycle is also described.

\section{Automatic Data-processing in University Admin- istration}

EACH year all the students admitted to King's College, Newcastle upon Tyne, are required to register before they start their work. The registration procedure involves the completion of a number of forms giving particulars about the student's date of birth, grant-giving body if any, place of residence, both while at home and at University, which out of a large range of courses he is intending to take, whether he is a new or returning student, an undergraduate or a graduate, and similar information to enable the University administration to have a complete record of the student, to arrange lecture room accommodation and to prepare the statistics required by various bodies. When done by hand this work occupies clerical staff for approximately one term. 'This year the task has been performed on the automatic digital computer in the University of Durham Computing Laboratory. The information on the forms was transferred to punched paper tape and processed on the computer. In just over two days all the lists and statistics required were produced. and the final lists distributed one week after the start of term. Further information about the tasks performed may be obtained from the Director, University Computer Laboratory, I Kensington Terrace, Newcastle upon Tyne, 2.

\section{The Ecological Society of Australia}

The Ecological Society of Australia was inaugurated at a meeting of plant and animal ecologists hold in Canberra on August 1. The objects of the Society are similar to those of the corresponding bodies in Great Britain and the United States. They include promotion of ecological research and the publication of the results of research, facilitation of exchange of ideas among ecologists working in different fields, and encouragement of the practical application of ecological principles. Management of the affairs of the Society is vested in a Council, of which the executive officers for the current financial year are : President, Dr. K. H. L. Key; Secretary, Mr. J. H. Calaby; Treasurer, Mr. A. G. McArthur. The con. stitution provides for the annual general meeting to be held in the month of August, with a further general moeting in association with each meeting of the Australian and New Zealand Association for the Advancement of Science; additional meetings may be called at the discretion of the Council. The subscription for the current year has been set at $£ 1$. The address of the Secretary is : c/o Wildlife Section, Commonwealth Scientific and Industrial Research Organization, P.O. Box 109, Canberra.

\section{The Institute of Fhysics and Physical Society:} Award;

The Council of the Institute of Physics and the Physical Society has made the following awards: Duddell Medal, to Dr. J. B. Adams, director-general of C.E.R.N. (European Organization for Nuclear Research), for his leadership of that toam; Charles Vernon Boys Prize, to Prof. A. W. Merrison, University of Liverpool, for his distinguished rescarch in experimental physics; Charles Chree Medal and Prize, to Dr. S. E. Forbush, of the Carnegie Institution of Washington, for his distinguished work on cosmic radiation. The following appointments have also been made: Guthrie Lecturer, Dr. D. Shoenberg, of the Royal Society Mond Laboratory, Cambridgo, to be Guthrie Lecturer for 1961; Thomas Young Orator, Dr. H. H. Hopkins, of the Imperial College of Science and Technology, to deliver the Thomes Young Oration in 1961.

\section{Royal Society: Awards}

Rutherford Memorial Appointment. Under the terms of tho scheme to commemorate the late Lord Rutherford of Nelson the Council of the Royal Society has appointed Mr. W. J. Darcey (University of Melbourne) to be Rutherford Scholar for 1960 for three years, to carry out research in exporimental nuclear physics at the Clarendon Laboratory, Oxford. Paul Instrument Fund. Awards of grants by the Paul Instrument Fund Committee have been made as follows: $£ 1,400$ per annum for two years, in supplement of a previous grant, to Prof. G. F. J. Garlick, Department of Physics, University of Hull, for the continuation of work on solid state light image amplifiers ; 22,000 in supplement of a previous grant, to Prof. D. Gabor, professor of applied electron physics at the Imperial College of Science and 